\title{
25
}

\section{Experiences of New Faculty in a Transitional Institution}

\author{
Michelle Yeo, Deb Bennett, Cari Merkley, Jane McNichol, Carlton Osakwe, \& Carolyn Pada \\ Mount Royal University
}

This research project studies the induction and socialization of new faculty at Mount Royal University, recently transitioned from college to undergraduate university status. There is extensive documentation in the literature on issues faced by new faculty in post-secondary institutions; however, very little is published on how a culture in flux may complicate this socialization. This project uses interpretive inquiry to study the experience over three successive years of new faculty experience. We use themes found in the prior literature of stress, time, socialization, and evaluation to structure our initial findings, but propose that a more complex framework is required to understand new faculty experience under these conditions of institutional transformation.

\section{Introduction}

$\mathrm{O}$ ur institution is undergoing a large scale transition from college to university. Mount Royal College, now University, has traditionally been an institution placing a high value on quality of instruction and the student experience. The institution continues to promote these values, along with an increased emphasis on faculty scholarship.

The transition has been accompanied by the hiring of large numbers of full-time faculty to support the expanded degree programs. More than a third of the full-time faculty at Mount Royal University (MRU) have been hired in the last three years. This phenomenon has had a significant impact on the institution, and its processes of induction and socialization.
This research project emerged as a small group of new faculty hired in 2007 to work together to understand their own experiences of induction and socialization in the midst of this institutional transition. There is extensive documentation in the literature on issues faced by new faculty in post-secondary institutions; however, very little is published on how a culture in flux may complicate this socialization. Our research question, therefore, is: "What is the lived experience of new faculty in a transitional institution?" Using interpretive inquiry, this project studies the experiences of full-time faculty, beginning with the experiences of the research group in 2007 (Phase I), and continuing with participants hired in 2008 (Phase II), and 2009 (Phase III). This paper 
reflects the preliminary findings from Phase I. Data analysis is still underway for Phases II and III.

\section{Literature in Brief}

Trowler and Knight (2000) argue that induction into faculty life is a complex socialization process with many unwritten rules. However, the work that has been done in the area of new faculty induction usually assumes a stable institution. Perry, Menec, and Struthers (1999) suggest that perceived control over work environments relates directly to a new faculty member's success in achieving tenure and in long term retention. In their study, "dual mission" institutions, where teaching and research are blended, resulted in a more difficult adjustment to the institution by new faculty (p. 205). MRU is in the midst of changing from a single mission (a focus on teaching) to a dual mission institution (teaching and scholarship). A search of the literature found little work has been done on the effect such a transition has on new faculty induction and adjustment. What little has been published references changing expectations for teaching and scholarship for faculty, but focuses on issues of legislation and governance (Dennison, 2006).

In a large scale North American study, Menges (1999) identified four key areas of concern to new faculty: stress, time, socialization, and evaluation. In the present study we began by using these themes to organize our thinking around transition. So far, while many issues faced by new faculty in general are shared by MRU newcomers, these concerns seem to be exacerbated by the transition. In our early stages of data analysis it is becoming evident that Menges' (1999) framework is inadequate to describe the complexity encountered by new faculty at MRU today. We hope to gain a clearer understanding of the nature of these potential differences through this study.

\section{Approach to the Inquiry}

Phase I of the project began in 2007 with the research group's self-study of their lived experiences. Because the project began as a group exploration, the investigators' perspectives were grounded within the research question and the narratives that were produced. In Phase II, nine participants drawn from the 2008 new hires were interviewed in the fall and spring using semi-structured interviews based on the themes generated during Phase I. These participants will be interviewed once more in 2009-10, while another group of participants from 2009 new hires will be interviewed in the fall and spring. Interpretive inquiry is a good fit for this research as it ensures a focus on the lived experiences of the participants. This approach requires researchers to situate themselves openly in relation to the research question and to become intentional in their consciousness of questioning, being the object and researcher simultaneously (Gadamer, 1999). Intentional lived experience takes time to assimilate, and our memory and construction of it over time shapes our reality in potentially profound ways (Gadamer, 1999). Extending the horizon of the lived experience of the original investigators in Phase I will help to deepen our understanding, and more richly present our common experiences (Gadamer, 1999) as new faculty in a transitional institution.

\section{Time and Stress}

\author{
"Time always seems to be the most limited \\ resource. I seem to get most things done \\ just in time."
}

Most new faculty members referred to time as a major source of concern. Competing demands, difficulty finding balance, and time management were issues identified by the participants. The constant nature of these demands is exacerbated by further work related to the transition occurring at MRU.

"I didn't actually predict how much time the 'in between' stuff would take - or how important it seems to the faculty. There seems to be more of the 'in between' work than anyone can actually do."

Time demands include traditional desires and responsibilities for new faculty such as teaching well while 
dealing with heavy course loads. The "in-between" responsibilities such as attendance at orientations and department meetings as well as committee work and connecting with one's team often resulted in feelings of being rushed. The institutional transition requires course development, increased paperwork accounting for scholarship activities, and committee work related to transitional processes. For some, additional expectations include finding time for Ph.D. work or other research. Ph.D. research was described as a pressure rather than an option by some participants.

"I'm running from appointment to appointment and not being terribly effective at anything once I get there."

Many new faculty members expressed the desire for a balance between their personal and professional lives. One participant identified the need to find balance before it affected their job performance. Powerful descriptions of having to let go of family traditions and routines were shared. Some described taking on too much as they felt it was important to consider how things appeared to colleagues.

Time and stress are closely connected issues. Stress was often related to the significant time pressures experienced by new faculty, but it is also related to adapting to a new (but unstable) culture, being asked to take on additional responsibilities (such as course co-ordination), and for some, teaching for the first time. One faculty member, when asked about how the transition was affecting her, explained that the time and stress pressures made those issues secondary:

"I found that I was aware of the transition issues/dynamic in the college, but I was so focused on survival (teaching and leading courses, research, staying awake, learning about the culture, attending meetings) that those issues became secondary."

Time and stress demands do not appear to diminish for new faculty in their second year. Although there was also a better understanding of the amount of time required in their new roles, it was expressed that expectations and demands simply grew for those seasoned by a year of work.

\section{Socialization and Evaluation}

Through formal affiliations such as committees and, perhaps more importantly, through informal relationships, new faculty have developed a sense of the power structure in the faculties and departments at MRU. As stated by one faculty member:

"I am becoming more attuned to interacting both formally and informally with my faculty colleagues. I have developed a few 'closer' relationships with coworkers, and this provides me with an invaluable source of information regarding who's who, and what's really going on."

While the informal relationships have created a "survival lifeline" for new faculty at MRU, their formation has been inhibited by the constant and sometimes chaotic reshuffling of office space required by growing programs. As opposed to the more competitive relationships that often exist between junior faculty at larger research institutions, new faculty at MRU appear to have the strongest associations with other junior faculty.

"My closest ties are to those who are also relatively new to the organization...I have found that there are personal and professional tensions between faculty members, and being a novice at navigating them I have found myself in a few uncomfortable spots throughout the year."

The evaluation process for tenure is, like the institution, in flux. Tenure candidates being evaluated and experienced tenured faculty doing the evaluating are both left to manage this uncertainty around expectations while guidelines are being developed. Many of the new faculty found the entire experience of evaluation quite daunting:

"It was nerve wracking to have an internal 
and an external peer observe my teaching..."

"I found the tenure binder process surprisingly time consuming."

"I'm not sure how much service makes good service for tenure purposes."

With this lack of clarity, the way scholarship will be evaluated stands out as one of the most major concerns of the new faculty at MRU.

\section{An Institution in Transition}

Particular tensions emerged in the data that can be linked specifically to the College's transformation. One participant wrote:

"The transition to undergraduate institution means the culture is in a state of major disruption. This exacerbates the typical pattern of tension always found between 'old' and 'new' one normally expects."

Several of the study participants reported feeling linked in the minds of their more established colleagues with the changes occurring at the institution, especially the increased emphasis on scholarship. As one participant put it:

"There is a certain sense of fear or threat, in some cases, that the new people represent."

The institutional transition has exacerbated what are perhaps inevitable tensions between new and established faculty. The institutional transition has had some positive outcomes for newly hired faculty as well. The cultural disruption has opened doors for new faculty. One participant stated:

"If I were at a traditional university, I would never have so quickly been afforded the kinds of opportunities that I have here..."
The institutional shift has been accompanied by the proliferation of new committees and expanded workloads for existing bodies. There are simply not enough tenured bodies to handle the increased service workload. As a result, many of the participants of the study have had the opportunity to participate in administrative work and institutional-level committees at an earlier stage of their career at MRU than they may have expected elsewhere. The increased service expectations, however, can add significantly to the workload and stress levels of new faculty as they attempt to navigate these committees without a lot of experience.

The data from Phase I, while congruent with previous work on new faculty, hints at emerging transitional issues. In our current work in Phases II and III, these issues take centre stage. We attribute this to the specific changes occurring at the institution during each year, for example, the introduction of separate research- and teaching-focused work patterns, the introduction of rank, and changes in the tenure system.

\section{Developing Conclusions}

Initial analysis of data from Phase II of this study further emphasizes the need for a more complex, dynamic theoretical framework. While stress, time, evaluation, and socialization continue to play a role in the experiences of faculty who joined MRU in the fall of 2008, many of the power dynamics identified by the original participants appear to have intensified. Through our analysis, we are beginning to conceptualize the experiences of new faculty as a series of competing discourses that create multi-faceted tensions in day-to-day work. While the tensions may not represent polar opposites, they are often experienced as forces that present dilemmas and compete for the time, energy, and attention of new faculty. This indeed represents a particular sense of being "between the tides" in our institution, as the 2009 Society for Teaching and Learning in Higher Education conference theme reflected more broadly.

New faculty members are both shaping and being shaped by the emerging institutional culture. 
Within this dynamic, the competing discourses of teaching versus scholarship are strong. A tension between the existing and emerging culture is evident throughout the data. Another strong dynamic involves the navigation of change without a roadmap. The competing discourses of what is known and unknown, and spoken and unspoken figure prominently. For example, some faculty expect to be evaluated on their scholarly activities, but it is uncertain how exactly scholarship will be defined and what will count. Rumour and hearsay play a significant role in the absence of concrete information.

Finally, also shifting is the pattern of relationships. For many of the new faculty in this study, their closest relationships are with other new faculty. The typical mentorship pattern is thus affected by the changes in the institution and by large numbers of new hires. In addition to more fully conceptualizing and exploring the tensions, dynamics, and competing discourses mentioned above, the precise nature of the mentorship pattern experienced under these particular circumstances will likely form a key focus of our continuing investigation.

\section{References}

Dennison, J.D. (2006). From community college to university: A personal commentary on the evolution of an institution. The Canadian Journal of Higher Education, 36(2), 107-125.

Gadamer, H.G. (1999). Truth and method (2 ${ }^{\text {nd }}$ ed.). New York: The Continuum Publishing Company.

Menges, R.J. (1999). Dilemmas of newly hired faculty. In R. J. Menges \& Associates (Eds.), Faculty in new jobs: A guide to settling in, becoming established, and building institutional support (pp. 19-38). San Francisco: Jossey-Bass.

Perry, R.P., Menec, V.H., \& Struthers, C.W. (1999). Feeling in control. In R. J. Menges \& Associates (Eds.), Faculty in new jobs: A guide to settling in, becoming established, and building institutional support (pp. 186-215). San Francisco: Jossey-Bass.

Trowler, P. \& Knight, P.T. (2000). Coming to know in higher education: Theorizing faculty entry to new work contexts. Higher Education, 19(1), 27-42.

\section{Biographies}

Michelle Yeo is an Assistant Professor in the Faculty of Teaching and Learning at Mount Royal University, working as a Faculty Development Consultant in the Academic Development Centre. Her scholarly interests include faculty development and experience, post secondary student experience, new literacies, and the future of post secondary education.

Deb Bennett is an Assistant Professor in the Department of Social Work and Disability Studies at Mount Royal University. Her scholarly interests include bereavement, disenfranchised grief experiences, the scholarship of teaching and learning, new faculty experiences, caregiver self care, and qualitative methodologies.

Cari Merkley is an Assistant Professor and the Nursing Liaison Librarian at Mount Royal University. Her research interests include academic librarianship and information literacy instruction.

Jane Stoneman McNichol is an Assistant Professor and Chair of the Public Relations Program in the Faculty of Communication Studies at Mount Royal University. Her scholarly interests include new faculty experiences in an institution in transition; barriers to learning financial concepts encountered by communication students; and impact of financial literacy on professional opportunities for communication graduates.

Carlton Osakwe is an Assistant Professor at Mount Royal University's Bissett School of Business. He holds a Ph.D. in Finance with a research focus on real options and adverse incentives. 
Carolyn Pada is a sessional instructor at Mount Royal University in the Faculty of Health and Community Studies, School of Nursing. Carolyn has published in the area of primary mental health supports in rural Alberta, including the Treaty 7 Nations. In addition to this project in the area of new faculty in a transitional institution, she is just concluding a research project on recruitment of Aboriginal youth to health careers, and Aboriginal curriculum content, and support in nursing programs. 